\title{
Blend of Roselle Calyx and Selected Fruit Modulates Testicular Redox Status and Sperm Quality of Diabetic Rats
}

\author{
Erukainure $\mathrm{OL}^{1 *}$, Okafor OY², Obode OC ${ }^{1}$, Ajayi A $^{1}$, Oluwole OB ${ }^{1}$, Oke OV, Osibanjo A $^{1}$, Ozumba A $^{1}$ and Elemo GN ${ }^{1}$
}

${ }^{1}$ Food Technology Division, Federal Institute of Industrial Research, Oshodi, Lagos, Nigeria

${ }^{2}$ Department of Natural Sciences, Albany State University, Albany Georgia, USA

\begin{abstract}
Hyperglyceamia-induced oxidative stress has been reported to be associated with testicular failure leading to sexual dysfunction, impotence and infertility. The effect of blend of roselle calyx and selected fruits on the testicular antioxidant activities and sperm quality of diabetic rats was investigated. Diabetes was induced by a single intraperitoneal injection of alloxan. Treatment lasted for 14 days after induction. The rats were sacrificed by cervical dislocation. Testicular tissues were used for assessment of GSH, catalase, SOD and lipid peroxidation. Sperm cells were analyzed for sperm motility, counts and abnormality. Induction of diabetes led to a significant decrease in GSH level, elevated SOD and catalase activities. These were significantly modified by the blend. The blends were observed to reduce malondialdehyde level. Induction of diabetes led to significant decrease in the studied sperm quality parameters, treatment with the blend significantly improved these qualities. This study indicates improved testicular antioxidant activities and sperm qualities by single and double doses of the fruit blend suggesting its protective potential against spermatotoxic and testicular toxicity in diabetics.
\end{abstract}

Keywords: Roselle calyx; Fruits; Sperm cells; SOD; CAT; MDA; GSH

\section{Introduction}

Diabetes has been described as a disease where the body produces little insulin and/or ceases to produce insulin, or becomes progressively resistant to its action [1]. It is a chronic disorder in metabolism of carbohydrates, proteins, and fat often characterized by hyperglycaemia [2].

The involvement of oxidative stress in the progress of diabetic complications has been well documented as well as its implication in diabetic pathogenesis [3]. Oxidative stress is caused by generation of free radicals such as reactive oxygen species (ROS). In physiological condition, the body synthesizes both free radicals and anti-oxidants [4]. Oxidative stress sets in when an imbalance occurs between these free radicals and antioxidants in favor of the free radicals [5]. Hyperglycaemia - induced oxidative stress have been reported to occur via increased glycolysis; auto-oxidation of glucose and non-enzymatic protein glycation [6].

The testis contains an elaborate array of antioxidant enzymes and free radical scavengers to protect against oxidative stress. This is of great importance as peroxidative damage is currently regarded as the major cause of impaired testicular functions. Hyperglyceamia have been reported to be associated with testicular failure leading to sexual dysfunction, impotence and infertility [6]. The lipids in sperm are the main substrates for peroxidation, which is induced by ROS generated by hyperglyceamia. This will ultimately lead to infertility in most men, characterized by low sperm count and motility [7].

The use of plants in the use in the management of diabetes has been well documented [8]. The medicinal properties of fruits have been reported. Their daily consumption has been associated with reduced risk of cancer, heart disease, premature aging, stress, diabetes, and fatigue (Shibumon). This is primarily due to the integrated action of oxygen radical scavengers such as $\beta$-carotene and ascorbic acid, calcium and dietary fiber [9]. Among such fruits are the pawpaw (Carica papaya L.), and grape (Citrus paradissi) fruits. Their anti-diabetic and/ or hypoglyceamic properties have been reported in several studies [1012]. Extracts of unripe pawpaw fruits (Carica papaya L.) have been used in treatment of diabetes [10,12], while grape fruits (Citrus paradissi) have been reported to exhibit antidiabetic effect by protecting beta cells in the pancreas $[11,12]$. However, the post-harvest shelf life of these fruits is very limited due to their perishable nature, thereby leading to wastage [9]. Blending of two or more fruit juices for the preparation of ready-to serve beverage have been shown to be a convenient alternative for ensuring a longer postharvest shelf life and utilization of these fruits $[9,13]$. Blending of fruit juice helps in improving flavor, taste, nutritive value, and reduces production cost $[9,14]$. Blending juices with other medicinal plants such roselle calyx (Hibiscuus sabdarifa) and guava leaves (Psidium guajava L.) improves the medicinal properties. Guava leaves have been shown to exhibit hypoglycemic effect in normal and diabetic rats [15]. Its ability to inhibit increase plasma glucose level in alloxan-induced diabetic rats has been reported [12]. Locally known as Zoborodo in Northern Nigeria, aqueous extract of roselle calyx has been demonstrated as having beneficial effects on anti-oxidation and lipidlowering in experimental diabetic studies [16]. A blend of these fruits with the mentioned medicinal plants would therefore form a natural health drink suitable for the treatment and/or management of diabetes and its related complication.

This paper reports the effect of blends of these fruits with roselle calyx (Hibiscuus sabdarifa) and guava leaves on the testicular antioxidant activities and sperm quality as well as blood glucose level of diabetic rats.

*Corresponding author: Erukainure OL, Food Technology Division, Federal Institute of Industrial Research, Oshodi, Lagos, Nigeria, Tel: +2348062179388; E-mail: loreks@yahoo.co.uk

Received August 08, 2012; Accepted September 10, 2012; Published September 15, 2012

Citation: Erukainure OL, Okafor OY, Obode OC, Ajayi A, Oluwole OB, et al. (2012) Blend of Roselle Calyx and Selected Fruit Modulates Testicular Redox Status and Sperm Quality of Diabetic Rats. J Diabetes Metab 3: 214. doi:10.4172/21556156.1000214

Copyright: ( 2012 Erukainure OL, et al. This is an open-access article distributed under the terms of the Creative Commons Attribution License, which permits unrestricted use, distribution, and reproduction in any medium, provided the original author and source are credited. 


\section{Materials and Methods}

\section{Plant materials}

Improved varieties of unripe pawpaw fruits (Carica papaya), grape fruits (Citrus paradissi) as well as guava leaves (Psidium guajava) were identified and obtained from National Horticultural Research Institute (NIHORT), Ibadan, Nigeria. Roselle calyx (Hibiscuus sabdarifa) was obtained from Mushin market in Lagos, Nigeria. The varieties of pawpaw, guava, and grape fruit identified and purchased were $\mathrm{Cg}$ variety of pawpaw, sweet grape and local guava respectively.

\section{Preparation of extracts}

Extracts of pawpaw fruit, guava leaf and grape fruit were produced using hot extraction methods as described by Okafor et al. [17]. Briefly, unripe pawpaw fruits were washed peeled, seeds were removed and the fruits were cut into smaller sizes. This was boiled for 30 minutes at $60^{\circ} \mathrm{C}$. The boiled fruits were then milled in a warring blender with the water in which they were boiled to get slurry, which was later filtered using a fine sieve to get the extract. Grape fruits were washed, peeled, cut into smaller pieces; seeds were removed and milled in a warring blender into slurry. The slurry was then filtered using a fine sieve. The guava leaves and the roselle calyx (Hibiscuus sabdarifa) were sorted, washed and boiled in water separately for 20 minutes, and the extracts were decanted.

\section{Blend formulation}

Varying proportion of the extracts were mixed together to get a blend as depicted on table 1. Roselle calyx (Hibiscus sabdariffa) was used as a carrier and part of the formulation. The blend was pasteurized at $80^{\circ} \mathrm{C}$.

\section{Animals}

Twenty male albino rats of wister strain weighing about 150-200 g were used for the study. They were fed on standard rat pellet diet and allowed to adapt for one week. They were provided water ad libitum and maintained under standard laboratory conditions of natural photo period of 12-hr light - dark cycle. The animals used in the present study were maintained in accordance with the approval of the Animal Ethical Committee, Federal Institute of Industrial Research, Lagos, Nigeria

\section{Induction of diabetes}

Diabetes was induced by a single intraperitoneal injection of 150 $\mathrm{mg} / \mathrm{kg}$ of alloxan monohydrate in normal saline water in a volume of about $3 \mathrm{~mL}$. After 72 hours, the diabetic rats (glucose level $>150 \mathrm{mg} / \mathrm{dl}$ ) were separated and used for the study.

\section{Experimental design}

The rats were divided into four groups, each consisting of five animals.

\section{Group 1 - Pelletized mouse chows}

Group 2 - Diabetic (Untreated)

\begin{tabular}{|l|l|}
\hline Extracts & Percentage (\%) \\
\hline Pawpaw & 30 \\
\hline Grape fruit & 10 \\
\hline Guava leaves & 20 \\
\hline Roselle calyx & 40 \\
\hline Sweetener & 10 tablets/litre \\
\hline
\end{tabular}

Table 1: Product formulation.

\section{Group 3 - Diabetic $+2.5 \mathrm{ml}$ of blend/bw}

Group 4 - Diabetic $+5 \mathrm{ml}$ of blend/bw

The rats were monitored daily for food and water intake, and body weight. The fruit blends were orally administered. Blood glucose levels of the rats were monitored on weekly basis with a glucometer. Treatment lasted for 14 days after induction. At the end of the treatment trials, the rats were fasted overnight and sacrificed by cervical dislocation.

\section{Preparation of tissue homogenates}

The testes were removed, rinsed in ice-cold $1.15 \% \mathrm{KCl}$ solution to wash off excess blood, blotted dry with filter paper and weighed. The organs were homogenized in four parts of homogenizing buffer and centrifuged at $10,000 \mathrm{~g}$ for $15 \mathrm{~min}$ in an ultracentrifuge at a temperature of $-2^{\circ} \mathrm{C}$ to get the mitochondrial fraction. The supernatant (postmitochondrial fraction) was decanted and stored at $-4^{\circ} \mathrm{C}$ for subsequent analysis. Each time the supernatant was outside the freezer, it was kept in ice bags.

\section{Determination of oxidative stress parameters}

Lipid peroxidation was determined by measuring malondialdehyde (MDA) formed by thiobarbituric acid reaction (TBAR) [18]. Catalase (CAT) activity was estimated by measuring the rate of decomposition of $\mathrm{H}_{2} \mathrm{O}_{2}$ [19]. The level of superoxide dismutase (SOD) activity was determined by the method of Kakkar et al. [20], while the method of Ellman [21] was adopted in estimating the activity of reduced glutathione (GSH).

\section{Evaluation of sperm quality}

The tail of the epididymis was cut into small pieces in $2 \mathrm{~mL}$ of normal saline and sperm collected by squeezing it gently on clean slide [22]. Sperm motility and count were evaluated using conventional methods [23]. Sperm abnormality was carried out by microscopical examination of the seminal smears stained with Eosin and Nigrosin stain. Presence of epithelial cells, triple phosphate crystals and oil droplets were also investigated.

\section{Statistical analysis}

Statistical significance was established using one-way analysis of variance (ANOVA), and data were reported as mean \pm standard deviation. Significant difference was established at $P<0.05$. Statistical analyses were carried out using SPSS for Windows, version 15.0 (SPSS Inc., Chicago, IL).

\section{Results}

\section{Blood glucose level}

Induction of diabetes led to an increase in the blood sugar level as depicted in figure 1 . Treatment with $2.5 \mathrm{ml}$ of the blend led to $13.25 \%$ reduction of the blood glucose level which was statistically significant $(p<0.05)$ at the first week of treatment, while at a double dose $(5.0$ $\mathrm{ml}$ ) a $56.62 \%$ reduction was observed. A further $33.95 \%$ reduction was observed in the single dose group (group 3) in the second week. However, there was a $32.90 \%$ increase in the blood glucose level of rats treated with a double dose compared to the first week of treatment.

\section{Antioxidant activities}

There were significant differences $(p<0.05)$ in all the studied antioxidant parameters. Induction of diabetes led to a significant $(\mathrm{p}<$ $0.05)$ reduction of GSH activity in the testes of the experimental rats 


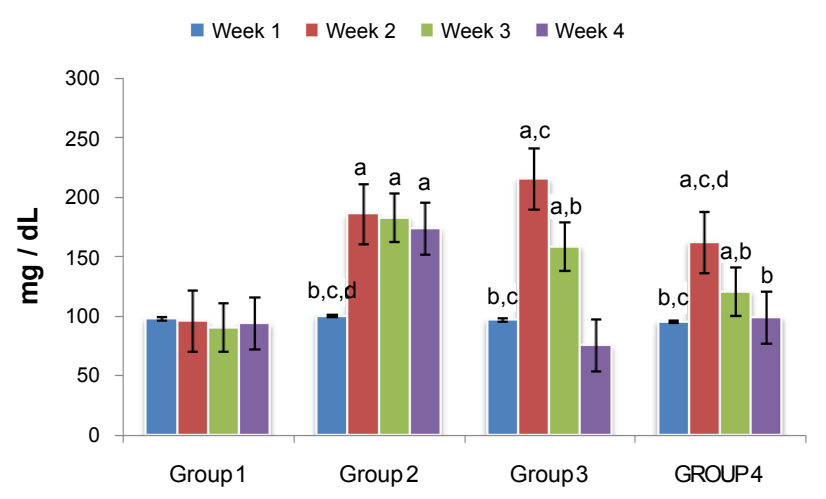

Figure 1: Blood glucose level of experimental groups. Values $=$ mean $\pm S D$; $\mathrm{n}=5$. Note: Values $=$ mean $+\mathrm{SD} ; \mathrm{n}=5 . \mathrm{a}=$ statistical significant $(\mathrm{p}<0.05)$ as compared with group $1 ; b=$ statistical significant $(p<0.05)$ as compared with group 2; $c=$ statistical significant $(p<0.05)$ as compared with group 3; $d=$ statistical significant $(p<0.05)$ as compared with group 4 .

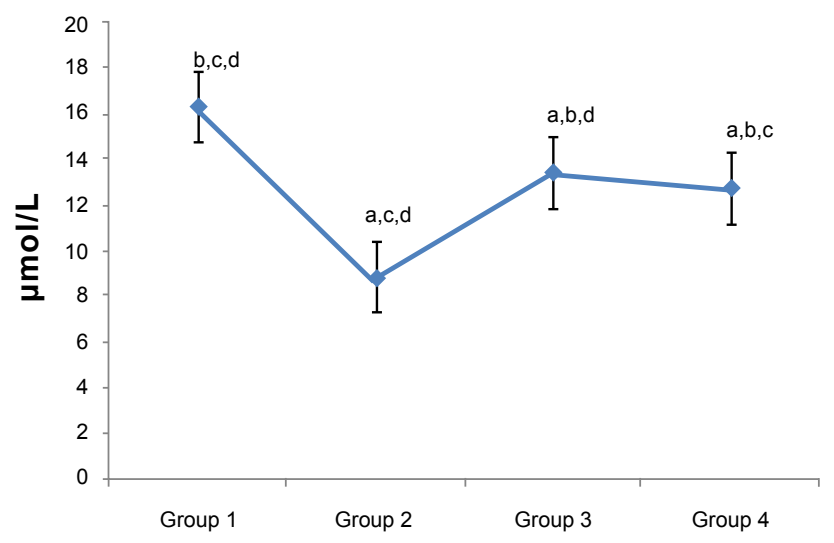

Figure 2: Effect of blends on GSH activities of testes in diabetic rats. Values = mean $\pm S D ; n=5$. Note: Values $=$ mean $+S D ; n=5$. a= statistical significant $(p<$ $0.05)$ as compared with group $1 ; b=$ statistical significant $(p<0.05)$ as compared with group 2; $c=$ statistical significant $(p<0.05)$ as compared with group $3 ; d=$ statistical significant $(p<0.05)$ as compared with group 4

(Figure 2). Treatment with the blend at both single and double doses significantly $(\mathrm{p}<0.05)$ increased the activity. There was an increase in the SOD activity in the untreated diabetic rats (group 2). Treatment with $2.5 \mathrm{ml}$ of the blend led to $12.59 \%$ decrease of the activity. However, it was further reduced in the double dose group (group 4) by $21.32 \%$ as shown in figure 3 . There was an increase in the catalase activity in the testes of the untreated diabetic rats as shown in figure 4. However, treatment with both doses reduced in its activity. Induction of diabetes led to increased level of MDA signifying lipid peroxidation (Figure 5). This was however reduced by $48.69 \%$ and $55.22 \%$ by single and double doses of the blends respectively.

\section{Sperm quality}

The effects of the blend at both single and double dose are shown in table 2. The sperm cells were observed to be grayish and opaque. They were also observed to be watery. Sperm count, and motility were significantly decreased in the untreated diabetic group in comparison to the control. These were observed to increase in the treated groups. However, treatment with single dose $(2.5 \mathrm{ml})$ had no effect on the motility. Sperm abnormality was observed to increase in the untreated group. Treatment with single and double dose had no effect on the abnormality. The concentration of pus cells was observed to be constant in all experimental groups. The concentration of epithelial cells were observed to increase in the untreated diabetic group, this was reduced in both treated groups. Triple phosphate crystal was observed in the sperm cells of the untreated diabetic group but absent in the treated. Oil droplets were observed in the sperm cells of the groups 1 and 4 respectively.

\section{Discussion}

The antioxidant capacity of juices (fruit blends) has been linked to in vivo protection from oxidative stress in numerous studies [24]. Various studies have also demonstrated the ability of these blends to scavenge free radicals and protect against lipid peroxidation in vitro [25]. These studies emphasized the protective effect of fruits against oxidative damage. These antioxidant activities can be explained in part by their dietary components especially the phytochemicals and vitamin C [26]. The testes are susceptible to oxidative stress despite the low oxygen tensions that typify the testicular cells. This is attributed to abundance of highly unsaturated fatty acids and the presence of potential ROS - generating systems [27]. The testes have developed

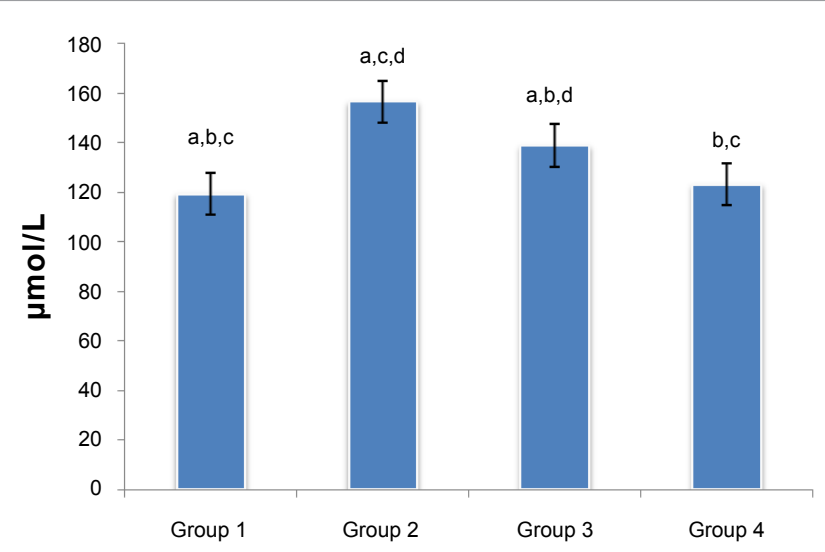

Figure 3: Effect of blends on SOD activities of testes in diabetic rats. Values = mean $\pm S D ; n=5$. Note: Values $=$ mean $+S D ; n=5$. a= statistical significant $(p<$ $0.05)$ as compared with group $1 ; b=$ statistical significant $(p<0.05)$ as compared with group 2; $c=$ statistical significant $(p<0.05)$ as compared with group $3 ; d=$ statistical significant $(p<0.05)$ as compared with group 4 .

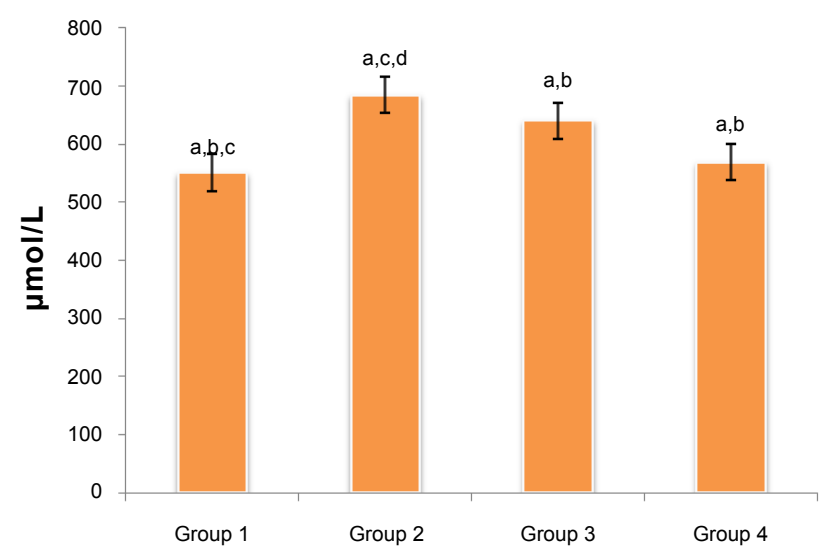

Figure 4: Effect of blends on CAT activities of testes in diabetic rats. Values = mean $\pm S D ; n=5$. Note: Values $=$ mean $+S D ; n=5$. $a=$ statistical significant $(p<$ $0.05)$ as compared with group $1 ; b=$ statistical significant $(p<0.05)$ as compared with group $2 ; c=$ statistical significant $(p<0.05)$ as compared with group $3 ; d=$ statistical significant $(p<0.05)$ as compared with group 4 . 


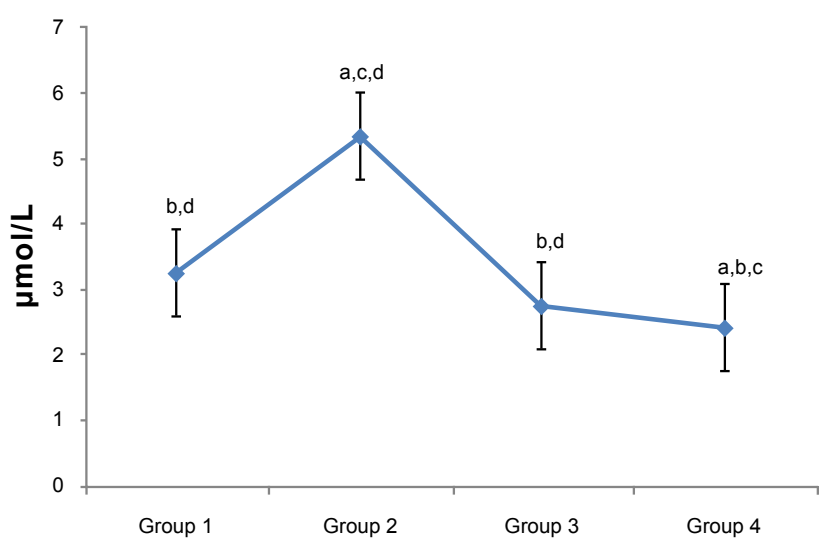

Figure 5: Effect of blends on LPO in testes in diabetic rats. Values $=$ mean \pm $\mathrm{SD} ; \mathrm{n}=5$. Note: Values = mean $+\mathrm{SD} ; \mathrm{n}=5$. $a=$ statistical significant $(p<0.05)$ as compared with group $1 ; b=$ statistical significant $(p<0.05)$ as compared with group 2; $c=$ statistical significant $(p<0.05)$ as compared with group $3 ; d=$ statistical significant $(p<0.05)$ as compared with group 4

\begin{tabular}{|l|l|l|l|l|}
\hline Parameters & Group 1 & Group 2 & Group 3 & Group 4 \\
\hline Motility & $50 \%$ & nil & nil & $40 \%$ \\
\hline Sperm Count & $800 \times 10^{6} \mathrm{ml}$ & $40 \times 10^{6} \mathrm{ml}$ & $75 \times 10^{6} \mathrm{ml}$ & $72 \times 10^{6} \mathrm{ml}$ \\
\hline Abnormal Count & $1 \%$ & $10 \%$ & $10 \%$ & $10 \%$ \\
\hline Epithelial Cells & + & ++ & + & + \\
\hline $\begin{array}{l}\text { Triple Phosphate } \\
\text { Crystal }\end{array}$ & nil & ++ & nil & nil \\
\hline Oil Droplet & ++ & nil & nil & +++ \\
\hline
\end{tabular}

Table 2: Effect of blend on sperm quality of diabetic rats.

an array of antioxidant systems comprising both enzymatic and nonenzymatic constituents to counteract this effect [27]. In diabetes these antioxidant systems are compromised, thus subjecting the testes to free radicals leading to testicular oxidative stress. The effect of blends of selected fruits with roselle calyx was investigated on testicular antioxidant activities and sperm quality in diabetic rats and reported in this paper.

The observed reduced blood glucose level portrays a hypoglyceamic effect of the blend. Our previous study on the chemical properties of the blend revealed the presence of a high percentage of flavonoid and phenols, which have been reported to have hypoglycemic potentials $[17,28]$. Their hypoglycemic activity and antioxidant potentials in normal and alloxan-induced diabetic rats have been studied [29]. This could explain the observed hypoglyceamic activities of the blend. Moreover, the anti-diabetic properties of extracts of the selected fruits have been reported [10-12].

Induction of diabetes by alloxan administration produced a marked oxidative impact as indicated by the significant increase in testicular lipid peroxidation and decrease in testicular antioxidants. This reflects the inhibitory action of alloxan on both enzymatic and non-enzymatic antioxidants in testes [30]. Alloxan exhibits its action by generating ROS resulting to destruction of the pancreatic $\beta$ cells thereby leading to diabetes [31].

Reduced cellular level of GSH has been reported to be a marker of oxidative stress [29]. The reduced level in the untreated diabetic group corresponds to previous studies which report reduced GSH level in diabetic patients and in experimental models $[32,33]$. This reduced GSH level indicates oxidative stress. The decrease in testicular GSH was reversed by the blend at both doses, indicating its antioxidant potentials.
Increased SOD and CAT activities due to oxidative stress have been reported [34]. Their observed increase in the testes of untreated diabetic rats might be attributed to hyperglycemia - induced oxidative stress. The importance of SOD in controlling $\mathrm{O}_{2}$ - leakage from testicular mitochondria has been reported [35]. Gu and Hecht [35] further reported that its mRNA is higher in the testes than the liver CAT catalyzes the decomposition of hydrogen peroxide $\left(\mathrm{H}_{2} \mathrm{O}_{2}\right)$ into less reactive gaseous oxygen and water molecules [36]. The present study demonstrated significant decreases in SOD and CAT activities in testes of rats treated with blends at both single and double dose.

Induction of lipid peroxidation (LPO) in diabetics has been observed in numerous tissues both in vitro and in vivo [37]. The testes are potent target owing to the high concentration of polyunsaturated fatty acids. In the present study, induction of diabetes enhanced the level of testicular lipid peroxidation in accordance to previous studies. The increased MDA level in the untreated diabetic rats depicts peroxidation of the lipids of the testicular tissues. Reduction of the MDA level by both doses of the blend reflects their protective potentials against hyperglyceamia - induced peroxidation of testicular membrane lipids.

Increasing evidence suggests that diabetes has an adverse effect on male reproduction function and oxidative stress may be involved [7]. This is evidenced by the sperm quality of the untreated diabetic rats. Their low sperm motility and count as well as percentage abnormality corresponds to previous studies on the sperm quality of diabetic rats $[7,27,38]$. Single dose of the blend was observed not to improve the sperm motility. However, at double dose the cell motility was restored. Insufficient sperm motility is a common cause of infertility, thus the improved motility at a double dose of the blend signifies improvement of the sperm quality and improved fertility. The observed improvement of the sperm count by both single and double doses of the blend portrays its potency in the management of the diabetic-induced spermatoxic and impotency in males. This could be attributed to the ability of the blend to improve the testicular antioxidant activities as evidenced by the enhanced antioxidant markers. The reduced concentration of epithelial cells and absence of triple phosphate crystals in the semen in the testes of the treated group further portrays the potency ability of the blend. Epithelial cells from the genitourinary tract, as well as leukocytes and immature germ cells are often present in ejaculates other than the spermatozoa which may be clinically relevant [39].

\section{Conclusion}

This paper indicates improved testicular antioxidant activities and sperm qualities by single and double doses of the fruit blend suggesting its protective potential against spermatotoxic and testicular toxicity in diabetic male rats.

\section{References}

1. Chakrabarti $R$, Rajagopalan $R$ (2002) Diabetes and insulin resistance associated disorders: Disease and the therapy. Curr Sci 83: 1533-1538.

2. Barar FSK (2000) Essentials of Pharmacotherapeutics. 3rd ed. S. Chand and Company Ltd: New Delhi.

3. Oberley LW (1988) Free radicals and diabetes. Free Radic Biol Med 5: 113 124

4. Wrighten SA, Piroli GG, Grillo CA, Reagan LP (2009) A look inside the diabetic brain: Contributors to diabetes-induced brain aging. Biochim Biophys Acta 1792: 444-453.

5. Benzie IF (2000) Evolution of antioxidant defence mechanisms. Eur J Nutr 39 53-61.

6. Ahmed RG (2005) The physiological and biochemical effects of diabetes on the 
Citation: Erukainure OL, Okafor OY, Obode OC, Ajayi A, Oluwole OB, et al. (2012) Blend of Roselle Calyx and Selected Fruit Modulates Testicular Redox Status and Sperm Quality of Diabetic Rats. J Diabetes Metab 3: 214. doi:10.4172/2155-6156.1000214

balance between oxidative stress and antioxidant defense system. Journal of Islamic Academic of Sciences 15: 31-42.

7. Hakim P, Sani HA, Noor MM (2008) Effects of gynura procumbens extract and glibenclamide on sperm quality and specific activity of testicular lactate dehydrogenase in streptozotocin-induced diabetic rats. Mal J Bioc Mol Biol 16 : $10-14$

8. Gupta RK, Kesari AN, Murthy PS, Chandra R, Tandan V, et al. (2005) Hypoglycemic and anti-diabetic effect of ethanolic extract of leaves of Annona Squamosa L. in experimental animals. J Ethnopharmacol 99: 75-81.

9. Bhardwaj RL, Pandey S (2011) Juice blends-a way of utilization of underutilized fruits, vegetables, and spices: a review. Crit Rev Food Sci Nutr 51: 563-570.

10. Oke JM. (1998) Antidiabetic potency of pawpaw. Afri J Biomed Res 1: 31- 34.

11. Maryuma Y, Matsuda H, Matsuda R, Kubo M, Hatano T, et al. (1985) Antidiabetic effect and effective components of the leaf of psidium guajava $\mathrm{L}$. (Part I). Shoyakugaku Zasshi 39: 261-269.

12. Lans CA (2006) Ethnomedicines used in Trinidad and Tobago for urinary problems and diabetes mellitus. J Ethnobiol Ethnomed 2: 45.

13. FAO (1989) Prevention of post-harvest food losses fruits, vegetables and roo crops a training manual. FAO, Rome.

14. Nwachukwu CU, Umeh CN, Kalu IG (2010) Identification and traditional uses of some common medicinal plants in Ezinihitte Mbaise L.G.A., of Imo State, Nigeria. Report Opinion 2: 1-8.

15. Ojewole JA (2006) Antiinflammatory and analgesic effects of Psidium guajava Linn. (Myrtaceae) leaf aqueous extract in rats and mice. Methods Find Exp Clin Pharmacol 28: 441-446.

16. Wang SC, Lee SF, Wang CJ, Lee CH, Lee WC, et al. (2011) Aqueous extract from Hibiscus sabdariffa linnaeus ameliorate diabetic nephropathy via regulating oxidative status and $\mathrm{Akt} / \mathrm{Bad} / 14-3-3 \gamma$ in an experimental animal model. Evid Based Complement Alternat Med 2011.

17. Okafor O, Daramola K, Pikuda Y, Oke O, Omosebi B, et al. (2010). Chemical Profile of Selected Fruit Extracts Used for Diabetes Control. In: Functional foods for chronic diseases, Vol 5: Diabetes and related diseases; Martirosyan DM, Abate N (Eds.). Food Science Publisher, Texas: 194-205.

18. Chowdhury $P$, Soulsby $M(2002)$ Lipid peroxidation in rat brain is increased by simulated weightlessness and decreased by a soy-protein diet. Ann Clin Lab Sci 32: 188-192

19. Chance B, Maehly AC (1955) Assay of catalase and peroxidase. Methods Enzymol 2: 764-775.

20. Kakkar P, Das B, Viswanathan PN (1984) A modified spectrophotometric assay of Superoxide Dismutase. Indian J Biochem Biophys 21: 130-132.

21. Ellman GL (1959) Tissue sulfhydryl groups. Arch Biochem Biophys 82: 70-77.

22. Shalaby MA, Mouneir SM (2010) Effect of Zingiber officinale roots and cinnamon zeylanicum bark on fertility of male diabetic rats. Glob Vet 5: 341-347.

23. Raji Y, Udoh US, Mewoyeka OO, Ononye FC, Bolarinwa AF (2003) Implication of endocrine malfunction in male infertility efficacy of Azadirachta indica extract in rats. Afr J Med Med Sci 32: 159-165.
24. Jensen GS,Wu X, Patterson KM, Barnes J, Carter SG, et al. (2008) In vitro and in vivo antioxidant and anti-inflammatory capacities of an antioxidant-rich fruit and berry juice blend. Results of a pilot and randomized, double-blinded placebo-controlled, crossover study. J Agric Food Chem 56: 8326-8333.

25. Erukainure OL, Okafor O, Oke OV, Daramola O, Ozumba A, et al. (2012). Protective potentials of blends of selected fruit extracts used for diabetes management against lipid peroxidation in hepatic cells and free radicals in vitro. Int J Trad Nat Med 1: 41-53.

26. Szeto YT, Tomlinson B, Benzie IF (2002) Total antioxidant and ascorbic acid content of fresh fruits and vegetables: implications for dietary planning and food preservation. Br J Nutr 87: 55-59.

27. Aitken RJ, Roman SD (2008) Antioxidant systems and oxidative stress in the testes. In: Molecular mechanism in spermatogenesis. Cheng CY (ed.) Landes Bioscience and Springer science + Business media.

28. Mukherjee PK, Maiti K, Mukherjee K, Houghton PJ (2006) Leads from Indian medicinal plants with hypoglycemic potentials. J Ethnopharmacol 106: 1-28.

29. Jorge AP, Horst $H$, de Sousa E, Pizzolatti MG, Silva FR (2004) Insulinomimetic effects of kaempferitrin on glycaemia and on $14 \mathrm{C}$-glucose uptake in rat soleus muscle. Chem Biol Interact 149: 89-96.

30. El-Missiry MA (1999) Enhanced testicular antioxidant system by ascorbic acid in alloxan diabetic rats. Comp Biochem Physiol C Pharmocol Toxicol Endocrinol 124: 233-237.

31. Lenzen S (2008) The mechanisms of alloxan- and streptozotocin-induced diabetes. Diabetologia 51: 216-226.

32. Obrosova IG, Fathallah L, Liu E, Nourooz-Zadeh J (2003) Early oxidative stress in diabetic kidney: effect of DL-alpha lipoic acid. Free Radic Biol Med 34: 186195

33. Dincer Y, Akcay T, Alademir Z, Ilkova H (2002) Effects of oxidative stress on glutathione pathway in red blood cells from patients with insulin-dependen diabetes mellitus. Metabolism 51: 1360-1362.

34. Onyema OO, Farombi EO, Emerole GO, Ukoha Al, Onyeze GO (2006) Effect of Vitamin $\mathrm{E}$ on Monosodium Glutamate induced hepatoxicity and oxidative stress in rats. Indian J Biochem Biophys 43: 20-24.

35. Gu W, Hecht NB (1996) Developmental expression of glutathione peroxidase, catalase, and manganese superoxide dismutase mRNAs during spermatogenesis in the mouse. J Androl 17: 256-262.

36. Chelikani P, Fita I, Loewen PC (2004) Diversity of structures and properties among catalases. Cell Mol Life Sci 61: 192-208.

37. Akondi RB, Kumar P, Annapurna A, Pujari M (2011) Protective effect of rutin and naringin on sperm quality in streptozotocin (stz) induced type 1 diabetic rats. Iranian Journal of Pharmaceutical Research 10: 585-596.

38. Amaral S, Moreno AJ, Santos MS, Seiça R, Ramalho-Santos J (2006) Effects of hyperglycemia on sperm and testicular cells of Goto-Kakizaki and streptozotocin-treated rat models for diabetes. Theriogenology 66: 2056 -2067.

39. Johanisson E, Campana A, Luthi R, de Agostini A (2000). Evaluation of 'round cells' in semen analysis: a comparative study. Hum Reprod Update 6: 404-412. 